\title{
SETTING PRIORITY OF STRATEGIES FOR ENVIRONMENTAL PROBLEMS ASSOCIATED WITH INDUSTRIALIZATION IN VIETNAM - - AN APPLICATION OF ANALYTIC HIERARCHY PROCESS TECHNIQUE--
}

\author{
Shinya Matsuda and Hiroshi Jonai \\ Department of Preventive Medicine and Community Health, University of Occupational and \\ Environmental Health, Japan \\ Iseigaoka Yahatanishi, Kitakyushu, Fukuoka 807-8555 Japan \\ Department of Occupational Diseases, National Institute of Industrial Health, Ministry of Labor, Japan \\ Nagao, Tama, Kawasaki, Kanagawa 214-8585 Japan \\ smatsuda@med.uoeh-u.ac.jp/ jonai@niih.go.jp
}

\begin{abstract}
To set the priorities among the strategies for the solution of environmental problems associated with industrialization in Vietnam, the authors analyzed opinions of 50 Vietnamese experts in this field by the Analytic Hierarchy Process (AHP) techniques. According to the focus group type of discussion with Vietnamese specialists, four background factors of environmental problems associated with industrialization were evaluated: shortage of human and materials resources, lack of appropriate environmental data, inappropriate administration system for environmental issue, and inadequate concern about environmental problems among workers and employers. Considering the relative importance of these four factors, the priorities within five strategies were evaluated by the AHP technique. The results showed that education of environmental problems for workers and employers was regarded the most important strategy, followed by reorganization of administration system and laws. for environment, training of personnel in the field of environmental problem, establishment of proper information system concerning environment, and development of research capacity in the field of environmental problems. It is expected that developed countries will help the Vietnamese government to implement these strategies.
\end{abstract}

\section{Introduction}

After the introduction of market economy since 1987, Vietnam has been realizing a rapid economic growth. For example, the average growth rate of GDP from 1991 to 1994 was $7.9 \%(6.0 \%$ in $1991,8.6 \%$ in $1992,8.1 \%$ in 1993 , and $8.8 \%$ in 1994). This rapid economic expansion have been realized by the increase in investment from foreign countries under the market economy. Economic growth will improve general condition of Vietnamese society by providing basic infrastructure such as safety water supply, sewage gathering system, route and electricity. However, it may also entail some negative effect on the society. Especially, problems of occupational health and environmental problems must be paid enough attention from the early stage of development because of its seriousness of impact on large population size. For example, most of tragic environmental problems occurred in Japan after the second World War, were caused by industrial activities (i.e., Minamata disease - intoxication by organic mercury expired from a chemical company producing fertilizer). Once such environmental problems occurred, its influence will last for a considerably long period. That is why a country under the rapid economic growth has to pay enough attention to the possibility of environmental damage. In fact, the Vietnamese government have much interesting in this subject, and they have clarified their attitude about this problem at the Earth summit in 1992; while they accept the importance of environmental problems, they condemned the responsibility of developed countries for the current environmental problems around the world, because most of the environmental problems are originally caused by the developed countries. Finally they have 
insisted on the responsibility of the developed countries to technically and financially assist developing countries in order to solve their problems (Matsuda, 1995a). Thus the developed countries are expected to respond to the demand from the developing countries in order to contribute to a sound economic development of them. We have an opportunity to participate in a cooperative research projects between Vietnam and Japan since 1994 under the title' of industrial activity and environmental problems in Vietnam. Through the four years experience, we recognized that there are a lot of environmental problems associated with industrial activities in Vietnam. It is clear that the Vietnamese government cannot solve all these problems by itself because of the shortage of human resources, materials and the adequate technology. Therefore, it is expected that some international collaborative projects will be organized for this subject. However, along with the slowdown of world economy, the developed countries also face to financial problems, which makes it difficult for them to respond to all the requests from the developing countries. Thus, we have to set the priorities among the programs in order to maximize the utility of collaboration under the financial limitation. In this purpose, we structured environmental problems associated with industrialization and strategies to solve such problems, and evaluated the priorities among strategies using the Analytic Hierarchy Process (AHP)(Saaty and Vargas, 1991).

\section{Studied population and methods}

\section{Construction of the model to be evaluated}

As a result of focus group type of discussions with several Vietnamese specialists of occupational and environmental problems, we structured the environmental problems associated with industrial activity in Vietnam and strategies to solve them as follows. As factors associated with the environmental problems associated with industrialization in Vietnam, four factors were evaluated: shortage of human and materials resources, lack of appropriate environmental data, inappropriate administration system for environmental issue, and inadequate concern about environmental problems among workers and employers. In order to solve these problems, the following five strategies were considered: training of personnel in the field of environmental problem, reorganization of administration system and laws for environment, education of environmental problems for workers and employers, establishment of proper information system concerning environment, and development of research capacity in the field of environmental problems. After evaluating the validity of this scheme through the discussion with Vietnamese specialists, we tried to evaluate the priority among these five strategies by using AHP (Analytic Hierarchy Process) techniques.

\section{Studied population}

At the moment of our visit to Hanoi in January 1997, we organized a seminar on industrial activities and environmental health at the National Institute of Labour Protection (NILP), Vietnam. There were about 60 participants in this seminar from the NILP, Hanoi Medical College, National Center for Environmental Technology, Ministries, and other institutes. At the end of the seminar, we tried to analyze the environmental problems associated with industrialization in Vietnam by the AHP technique with 50 participants ( 13 medical doctors, 25 engineers, and 12 persons in administration).

\section{Opinion survey in the field}

At the first level, four factors were compared each other regarding their relative importance. Then, five strategies were compared with each other regarding their relative usefulness in order to cope with each of the four factors mentioned above. For example, the question is as follow: In order to improve the problem related to the shortage of human and materials resources, which strategy is the most important, "training of personnel in the field of environmental problem " or "reorganization of administration system and laws for environment?" Participants were required to answer all statements of comparison in a questionnaire method. Then, in order to obtain each value of component in the pairwise comparison matrix, the geometric mean of the answers of 50 participants was calculated.

Results 
Table 1 shows weights of each background factor calculated by the comparison matrix. Inadequate concern about environmental problems among workers and employers was detected as the most important problem, followed by inappropriate administration system for environmental issue, shortage of human and material resources, and lack of appropriate data.

Table 1 Comparison of back ground factors of environmental problems associated with industrialization in Vietnam

\begin{tabular}{l|cccc|c} 
& F1 & F2 & F3 & F4 & Priorities \\
& & & & & \\
F1 & 1.000 & 1.025 & 0.862 & 1.250 & 0.252 \\
F2 & & 1.000 & 0.906 & 1.523 & 0.264 \\
F3 & & & 1.000 & 1.903 & 0.306 \\
F4 & & & & 1.000 & 0.178
\end{tabular}

F1: Shortage of human and materials resources

F2: Inappropriate administration system for environment

F3: Inadequate concern about environmental problems among workers and employers

F4: Lack of appropriate data

Table 2 shows the matrix of weights which represents the relative importance of each strategy in solving these problems. For example, to solve the problem of shortage of human and material resources, education of environmental problems for workers and employers was regarded the most important, followed by reorganization of administration system and laws for environment, training of personnel in the field of environmental problem, development of research capacity in the field of environmental problems and establishment of proper information system concerning environment.

Table 2 Comparison of strategies with respect to back ground factors of environmental problems associated with industrialization in Viet

Shortage of human and materials resources
\begin{tabular}{l|cccccc} 
\\
S1 & S2 & S3 & S4 & S5 & Priorities \\
S1 & 1.000 & 1.025 & 0.707 & 1.346 & 0.976 & 0.197 \\
S2 & & 1.000 & 0.928 & 1.346 & 1.104 & 0.210 \\
S3 & & & 1.000 & 1.486 & 1.219 & 0.243 \\
S4 & & & & 1.000 & 0.952 & 0.161 \\
S5 & & & & & 1.000 & 0.189
\end{tabular}

\begin{tabular}{l|ccccc|c}
\multicolumn{8}{l}{ Inappropriate administration system for environment } \\
\begin{tabular}{l|cccccc} 
S1 & S2 & S3 & S4 & S5 & Priorities \\
S1 & 1.000 & 0.862 & 1.025 & 1.104 & 1.104 & 0.201 \\
S2 & & 1.000 & 1.313 & 1.313 & 1.486 & 0.247 \\
S3 & & & 1.000 & 1.077 & 1.051 & 0.192 \\
S4 & & & & 1.000 & 1.132 & 0.186 \\
S5 & & & & & 1.000 & 0.173
\end{tabular}
\end{tabular}

Inadequate concern about environmental problems among workers and employers

\begin{tabular}{|c|c|c|c|c|c|c|c|c|c|c|c|c|c|}
\hline & S1 & S2 & S3 & S4 & S5 & Priorities & & S1 & \$2 & S3 & S4 & S5 & Priorities \\
\hline S1 & 1.000 & 0.952 & 0.625 & 1.132 & 1.250 & 0.191 & S1 & 1.000 & 0.952 & 0.906 & 0.707 & 0.952 & 0.178 \\
\hline S2 & & 1.000 & 1.000 & 1.160 & 1.380 & 0.219 & S2 & & 1.000 & 1.346 & 0.841 & 1.219 & 0.214 \\
\hline S3 & & & 1.000 & 1.486 & 1.601 & 0.258 & S3 & & & 1.000 & 0.884 & 0.906 & 0.183 \\
\hline S4 & & & & 1.000 & 1.104 & 0.175 & S4 & & & & 1.000 & 1.523 & 0.245 \\
\hline S5 & & & & & 1.000 & 0.157 & S5 & & & & & 1.000 & 0.180 \\
\hline
\end{tabular}

S1: Training of personnel in the field of environmental problem

S2: Reorganization of administration system and laws for environment

S3: Education of environmental problems for workers and employers

S4: Establishment of proper information system concerning environment

S5: Development of research capacity in the field of environmental problem

Table 3 shows the relative importance of the five strategies calculated by the AHP method. Education of environmental problems for workers and employers was regarded the most important strategy, followed by reorganization of administration system and laws for environment, training of personnel in the field of environmental problem, establishment of proper information system concerning environment, and development of research capacity in the field of environmental problems. 
Table 3 Composite priorities in order to solve environmental problems associated with industrialization in Vietnam

$\begin{array}{lccccc} & \text { F1 } & \text { F2 } & \text { F3 } & \text { F4 } & \begin{array}{c}\text { Composite } \\ \text { Priorities }\end{array} \\ & 0.250 & 0.260 & 0.310 & 0.180 & \\ \text { S1 } & 0.197 & 0.201 & 0.191 & 0.178 & 0.192 \\ \text { S2 } & 0.210 & 0.247 & 0.219 & 0.214 & 0.223 \\ \text { S3 } & 0.243 & 0.192 & 0.258 & 0.183 & 0.224 \\ \text { S4 } & 0.161 & 0.186 & 0.175 & 0.245 & 0.187 \\ \text { S5 } & 0.189 & 0.174 & 0.157 & 0.180 & 0.174\end{array}$

F1: Shortage of human and materials resources

F2: Inappropriate administration system for environment

F3: Inadequate concern about environmental problems among workers and emplo

F4: Lack of appropriate data

S1: Training of personnel in the field of environmental problem

S2: Reorganization of administration system and laws for environment

S3: Education of environmental problems for workers and employers

S4: Establishment of proper information system concerning environment

S5: Development of research capacity in the field of environmental problem

\section{Discussion}

\section{About the AHP method}

In the present analysis, the authors employed the AHP technique in order to investigate relative importance among possible strategies for the solution of environmental problems associated with industrialization in Vietnam. This method, if applied properly, is very useful for the decision making process. However, there are some cautions that should be headed when interpreting the results. The most important problem is that the structurization of the studied problem can be heavily influenced by the knowledge and capacity of the investigator. While we have a four-years-experience of the field study in Vietnam, there still remains that our scope might be limited within our particular interest. Another important problem is that the results will vary according to the characteristics of members in the studied group. For example, the opinion of employers and workers. might be different from that of studied members. In this sense, the present results may be favorable to researchers and administrators, and therefore cannot be regarded as definitive ones. However, it should be noted that the planning must be a continuous process and not a one point activity. We believe that it is important to continue this type of discussion to ameliorate the quality of the collaborative programs.

\section{About the results}

According to the AHP analysis, the education of environmental problems for the workers and employers was evaluated as the most important strategy. After the introduction of a new market economy, the incentive for higher productivity has become very strong among workers and employers. Thus, environmental problems have reverted to second place. For example, in our previous study, over $60 \%$ of workers replied that they would accept hazardous working condition and environmental pollution in order to earn more money and to develop the national economy as rapid as possible (Matsuda, 1995b). It is no doubt that education be the most important strategy to change this attitude and thereby to prevent environmental problems associated with industrialization. However, this strategy is rather difficult to be implemented in the actual situation of Vietnam, because its requires additional financial costs and because its effect will not be expected immediately. In order to motivate the employers to have enough attention to 
environmental problems, some really effective regulatory method should be installed. The introduction of environmental tax or the obligation of environmental impact assessment before installation of new factory or workshop are such strategies. In fact, according to the law on the environmental protection and its related decrees, investing companies are obliged to conduct the environmental impact assessment (EIA) before starting production and then to report the EIA results to the government for obtaining the approval of starting the production. Each investment program is required to allocate 0.05 to $0.3 \%$ of its total invested capital to EIA. With the obligation of EIA, the Vietnamese government can motivate the investor to be more conscious of environmental issues and thereby facilitate the installation of clean production system. However, the obligation of EIA are not applied to the already existing factories. In most of the cases, these existing factories use obsolete equipment without any environment protective devices and causes environmental pollution around the factories. Especially the existing small-scale factories becomes important sources of environmental pollution in urban residential areas. After the introduction of the new market economy, many small scale factories (usually family-managed factories) have been created in the residential areas. Most of them were originally non-toxic (i.e., shoe makers, clothing, etc.) and thereby there existence were allowed in the residential zone. Along with the chemicalization of the industry, however, many of them become to use some toxic chemical substances and causes environmental pollution (Cao, 1995). The problem is that they are using hazardous substances without appropriate knowledge. As the turnover rate of workers is very rapid in such factories, education for the employers is the most important. Given the financial difficulties of many polluting firms which have obsolete equipment and an uncertain future in the light of recent trend in the industrial sector, the employment concern of the municipal government, and the lack of incremental resources for the pollution control, many plants that violate the environmental standards can do little more than make small improvement in housekeeping, and the government generally do not press them. Under such a situation, one of the most available strategies is to focus initially on the regulation of a limited number of pollutants related to human health (i.e., $\mathrm{SO}_{2}$, dust, $\mathrm{CO}$, Lead, and other heavy metals). The advantage of this strategy is a better chance of achieving early success and thereby enlightening workers and employers. Also the combination with the worker's participating strategy (Kogi, Phoon, and Thurman, 1989) will be useful to empower the workers.

The reorganization of administrative system and laws for the environment was evaluated as the second most important strategy. In fact, the Vietnamese government has established fundamental laws for environmental matters and successively organized administrative bodies for this task from the central to local level. The State Committee for Sciences (SCS) was restructured in October 1992 to form the Ministry of Science, Technology and Environment (MOSTE). The Law on the Environmental Protection approved by the National Assembly in December 1993, and the implementing regulations to it (Decree $175 /$ CP in October 1994), sets out the functions of MOSTE as follows; management of research issues, technology and environment; preparation of environment assessment of the economy and of environmental action plans; implementing the Law on the environmental protection and its associating decrees; codification of regulation and standards; evaluating environmental impact assessment and coordination with the MPI and other related agencies. One department of MOSTE, named as Department of Environment and Natural Resources, which became the National Environment Agency (NEA) in 1994, has the responsibility of undertaking the public administration of the environmental protection on behalf of the Minister of MOSTE. At the provincial level, the Department of Science, Technology and Environment (DOSTE) has formal authority to review and to comment on environmental aspects of the investment applications and to resolve pollution related dispute on behalf of the People's Committee. However, most of them lack trained staffs and financial resources. To make this system work adequately, it is necessary to have sufficient number of trained staffs as well as political tools such as information, inspection activities, and penalties enforced by law. In the current situation, however, there is no adequate environmental information system and no adequate inspection activities, with the result that penalties defined in the law are rarely applied. The complicated administrative system makes the situation worse. For example, the investment program relates to several ministries and governmental bodies, i.e., the ministry of industry, ministry of electricity, the central government and the local government. Furthermore, there are many laws which contain some articles related to environmental issues; i.e. the law on the foreign investment, the land law, and the law on the public health. However, there are little consideration about the compatibility among different laws. It is very common that different governmental 
bodies sometimes have different views on the environmental protection and investment programs. This situation has a possibility to disturb the implementation of integrated programs for industrialization and environmental protection. In order to facilitate the communication among the associated persons, the reorganization of the administrative system will be expected.

Another important problem associated with administration is the absence of adequate national standards limiting industrial emissions. Employed standards are different between central and local governments, as well as between different industrial sectors, and most of them do not include technical guidelines for sampling, measurement and analysis of pollutants. Thus, these standards are not sufficiently applied in order to prevent the pollution. It is recommended that existing standards will be changed into ISO/WHO standards.

So far as the training of personnel in the field of environmental problem, capacity building at the provincial level is critical. After the introduction of market economy, local governments managed enterprises have been the partners of the foreign investment in many cases. As already mentioned, it is obligatory for the investors to follow the EIA process before the implementation of projects. This EIA assessment is usually conducted by the Vietnamese organization, i.e., Center for Environmental Technology at the central level and facilities associated with DOSTE at the provincial level. As easily imagined, it is very difficult for the local facilities to appropriately conduct EIA because of the shortage of trained staffs and materials. This condition causes many problems, such as the delay in the implementation of investment project and environmental damage due to inappropriate EIA. Therefore, it should be strongly recommended that some training courses of environmental assessment be organized for the Vietnamese staffs of local governments in order to transfer necessary technology and skill for environmental control.

The establishment nation-wide information system, such as environmental monitoring systems will be required in order to implement an effective environmental control. However it will cost very expensive. In order to establish a proper environmental information system, it will be the most cost-effective to conduct epidemiological studies in some typical industrial zone in order to evaluate the importance of the environmental damage caused by the rapid industrialization. These projects will be also very useful for the capacity building of the researchers, personnel in the administration and epidemiologists who are the most wanted in the third world.

Although the development of research capacity in the field of environmental problems was not highly evaluated, we think that assistance in the field of research is very important target for international cooperative programs. Through the collaborative projects, we shall be able to share knowledge and skills and to train personnel in this field. With enough number of trained local staffs, they can continue the proper environmental programs by themselves even after the end of international collaborative programs. It is expected that many international collaborative programs will be incorporated in Vietnam.

\section{References}

Cao V.S. (1995). Environment and bioresources of Vietnam. The GIOI Publishers: Hanoi.

Kogi K., Phoon W.O., Thurman E. (1989). Low-cost ways of improving working conditions: 100 examples from Asia, ILO: Geneva.

Matsuda S. (1995a) "The state of environmental problems in Vietnam" $J J P H, 42,413-420$.

Matsuda S.(1995b). "An analysis of the current situation of occupational safety and health in Vietnam" $J$. Science of Labour 71, 49-62.(in Japanese)

Saaty T.L., Vargas L.V. (1991). Prediction, projection, and forecasting, Kluwer Academic: Massachusetts. 


\title{
CONSIDERATION ABOUT COMPREHENSIVE DEVELOPMENT OF URBAN ECONOMY OF SHANXI PROVINCE OF CHINA
}

\author{
Li Changying and Wang Tianbao \\ Department of Industrial \& Commercial Management \\ Shanxi University of Fiance \& Economics \\ Tianyuan, Shanxi, P.R. of China \\ Strarsky@public.ty.sx.cn
}

\begin{abstract}
When the $21^{\text {st }}$ century is just around the corner, the knowledge economy is coming into being quietly. A common problem is posed to all professionals and trades of the whole society, which is how to forge ahead towards the knowledge economy times promptly. How to fit in with the needs of the market economy, how to integrate sci-tech with economic increase closely and how to transform sci-tech into productivity. Therefore the development of sci-tech and actual application and propagation of theoretical knowledge have become the heart of economic development. The urban economy development plays a decisive role for the development of the whole national economy. The developing history of the cities in the world has proved that quickening the tempo of urban economy development. Grasping the opportunity of development to strengthen urban comprehensive capabilities and heightening the level of urbanization are only road toward the modernization focusing on this central issue. This paper makes an evaluation for comprehensive economic capacities of twenty cities in Shanxi province with the propose of giving play to strong points of each city of city of itself and exploiting the potential factors for economic development of each city at the same time and providing scientific basis for urban developing programme of Shanxi Province adopting AHP method, an evaluation sequencing method with the combination of the quantitative with the qualitative, proposed by professor T. L. Saaty of Pittsburgh University of U.S.A.
\end{abstract}

